increasing age and their presumably less sensitivity to sexual odors, especially those laid down in linear apparatuses. On the other hand, there has been some suggestion in data collected in this laboratory that males are also more sensitive to variations in sucrose concentration (or at least that they are more attracted by higher concentrations). Thus, while the choice of one sex or the other should of course be made in accordance with the particular requirements of the experiment, it is reassuring that use of female rats is not generally contra-indicated for instrumental appetitive learning on the basis of their estrous cycle.

\section{REFERENCES}

COURTNEY, R. J., JR., REID, L. D., \& WASDEN, R. E. Suppression of running times by olfactory stimuli. Psychonomic Science, 1968, 12, 315-316.

DAVIS, S. F, \& LUDVIGSON, H. W. The "depression effect" and the problem of odor control. Psychonomic Science, 1969, 14, 93-94.

HITT, F. C., GERALL, A. A., \& GIANTONIO, G. W. Detection of estrous activity cycle by 1-hour samples of running behavior. Psychonomic Science, 1968, 10, 159-160.
LESTER, D. Effects of olfactory stimuli on Y-maze exploration of rats. Psychonomic Science, 1968, 12, 97.

LUDVIGSON, H. W., \& SYTSMA, D. The sweet smell of success: Apparent double alternation in the rat. Psychonomic Science, 1967, 9, 283-284.

MARX, M. H., TOMBAUGH, T. N., HATCH, R. S., \& TOMBAUGH, J. W. Controlled operant conditioning boxes with discrete-trial programming for multiple experimental use. Perceptual \& Motor Skills, 1965, 21, 247-254.

McHOSE, J. H., \& LUDVIGSON, H. W. Differential conditioning with nondifferential reinforcement. Psychonomic Science, 1966, 6, 485-486.

MOSS, R. L. Changes in bar-press duration accompanying the estrous cycle. Journal of Comparative \& Physiological Psychology, 1968, 66, $460-466$.

\section{NOTE}

1. This research was supported in part by United States Public Health Service Research Grant HD-00895 from the National Institute of Child Health and Human Development, Research Career Award 1-K6-MH-22,023 from the National Institute of Mental Health, and National Science Foundation Research Grant GB $\mathbf{5 8 3}$.

\title{
A measure of pronunciability of CVC trigrams'
}

\section{CALVIN F. NODINE2 and JAMES V. HARDT, CARNEGIE- MELLON UNIVERSITY, Pittsburgh, Pa. 15213}

All 2100 CVC trigrams were scaled for pronunciability by measuring pronunciation latency (P Lat). The resulting distribution of P Lat scores was extremely leptokurtic and positively skewed. Scores ranged from a minimum of $.531 \mathrm{sec}$ to a maximum of $1.726 \mathrm{sec}$. Average P Lat was $.81 \mathrm{sec}$. The relationship of $P$ Lat to Archer meaningfulness was linear; however, the degree of relationship was slight $(r=-.37)$. This finding is interpreted as indicating that P Lat is relatively free of bias from such other stimulus attributes as meaningfulness. As such, $P$ Lat is viewed as reflecting a basic processing time for such stimulus materials.

The demonstrated potency of meaningfulness in verbal learning has been amply attested to in several reviews (e.g., Goss \& Nodine, 1965; Underwood \& Schulz, 1960). One of the important underlying dimensions of meaningfulness is pronunciability. Several studies have reported high positive correlations between rated pronunciability and rated meaningfulness (e.g., Underwood \& Schulz, 1960; Wilson \& Becknell, 1961). Recently, Gorfein (1967) used pronunciation latency (P Lat) as a measure of pronunciability. Using 144 CVCs from Underwood and Schulz's list, Gorfein obtained an $\mathrm{r}$ of -.66 between P Lat and rated meaningfulness. This correlation is lower than those reported with rated pronunciability, which led Gorfein to argue that these latter correlations are spuriously high due to significant commonality between ratings of pronunciability and meaningfulness.

One shortcoming of all of these studies, whether they use ratings or P Lat to measure pronunciability, is that they are limited to small subsets of CVC trigrams. This situation may present an unrepresentative picture of the relationship between pronunciability and meaningfulness. The present experiment corrects this situation by scaling the pronuneiability of all 2100 CVC trigrams using $P$ Lat as a measure thereof.

\section{Materials}

\section{METHOD}

All possible CVC trigram combinations were used except those containing duplication of consonants in initial and terminal positions (e.g." "BAB") and those containing "Y" as a vowel (e.g., "BYC"). An alphabetical listing of these 2100 trigrams was randomized by using the ordinal positions of each item as inputs in a computer program that generated new random ordinal positions for each item as outputs. The resulting random listing of CVCs was divided into four sublists of 525 items each.

\section{Subjects}

Forty Ss were randomly assigned to one of four sublists containing 525 trigrams each. The order of presentation for each sublist was constant for all Ss. The latter were undergraduates fulfilling course requirements in psychology. There were nine males and one female for each sublist. Each $S$ was run individually and was read the following instructions:

"This is an experiment designed to see how people pronounce nonsense syllables. When the experiment begins, nonsense syllables will appear one at a time on the screen in front of you. I want you to try and pronounce each of these as carefully as possible. Each nonsense syllable will appear on the screen for $1 \mathrm{sec}$, or until you pronounce it. If you have not pronounced it within $1 \mathrm{sec}$, it will go off, but you will still have $2 \mathrm{sec}$ to make a response before the next syllable appears. Try to be careful to give the correct pronunciation. Do you have any questions?"

After the instructions were read, the sensitivity of the voice key was adjusted to each individual by having $S$ articulate pauses (e.g., ahh, err).

\section{Apparatus and Procedure}

Stimulus presentation and data collection were accomplished by means of a DDP-116 computer (Control Data Corporation) and auxilliary equipment that included oscilloscope, voice key, and microphone. The microphone was positioned 6 in. from S's 
lips and held in place by a "chesty" microphone support.

The three letters of each trigram were displayed as 1-in. capitals on an oscilloscope. The $S$ was seated approximately $2 \mathrm{ft}$ in front of the display. As each trigram was presented, P Lat was obtained by measuring the time between onset of the stimulus and the initiation of S's pronunciation response, which activated the voice key. The measurements were computed to within $1 / 100 \mathrm{sec}$ and punched out on paper tape.

An auxilliary oscilloscope and sound system was used by $E$ to monitor Ss' pronunciation response and to check for extraneous sounds (e.g., coughs, laughs, sneezes, etc.) that would activate the voice key and result in erroneous times. Ss were disqualified from the experiment if their records contained more than $6 \%$ erroneous response (32/525 errors). Three additional Ss were disqualified on this basis. Each $\mathrm{S}$ was required to pronounce each of the 525 trigrams of a sublist twice. A self-paced format was used in order to obtain minimum times for pronunciation of each trigram. It was assumed that the $\mathrm{P}$ Lat scores obtained under the self-paced format would be influenced less by associative factors than those obtained under a constant rate.

A maximum of $3 \mathrm{sec}$ response time was allowed for pronouncing each trigram. This time was variable depending on Ss' response latency, and was subdivided into a maximum display time of $1 \mathrm{sec}$ followed by a maximum "off" time of $2 \mathrm{sec}$ during which the display was dark but $S$ could still respond. The initiation of a response by $S$ at any point during the 3-sec period would activate the voice key and terminate the presentation sequence for that trigram. If $S$ initiated a response during the display time, the presentation sequence was interrupted, and, after a brief pause $(.25 \mathrm{sec})$, the presentation sequence was repeated with a new item. Under the self-paced format Display Time = MIN(1, P Lat) sec, and Response Time = MIN(3, P Lat) sec. For Display Time, MIN refers to the minimal value of either $1 \mathrm{sec}$ or P Lat, whichever is less; for Response Time, it refers to $3 \mathrm{sec}$ or P Lat, whichever is less.

Using this format, the average time required to pronounce all 525 items was $12.5 \mathrm{~min}$. If the presentation rate had been constant at $3 \mathrm{sec}$ per item, it would have taken over $26 \mathrm{~min}$ to pronounce all 525 items. After a brief rest period $(2 \mathrm{~min})$ the list was repeated (same order) and $S$ was again required to pronounce each trigram. The average time to complete the task on the second repetition was $11 \mathrm{~min}$.

\section{Distribution of Scores}

\section{RESULTS AND DISCUSSION}

$P$ Lat represents mean latency based on the scores of $10 \mathrm{Ss}^{3}$ The $P$ Lat scores for all 2100 CVC trigrams on Trial 1 only are presented in Fig. 1, which shows the frequency of $P$ Lat values for successive $.04-\mathrm{sec}$ intervals from $0.531 \mathrm{sec}$ to $1.725 \mathrm{sec}$. All CVCs with latencies falling within the .04-sec intervals are printed in a single column one above the other. The result is a frequency histogram with the 2100 trigrams fitling the columns. As such, the histogram not only shows the overall shape of the latency distribution, but also presents the data in a way that allows one to select trigrams from any given latency range by simply referring to the column that spans the desired range of values. ${ }^{4}$ Within each column, latencies increase from bottom to top.

The $P$ Lat values of trigrams in a given column are greater than the lower bound and less than or equal to the upper bound. Thus, the P Lat of a trigram can attain the upper bound of the column, but, with the exception of the first column, cannot attain the lower bound.

The average P Lat (overall) on Trial 1 was $.81 \mathrm{sec}$ with an SD of $.27 \mathrm{sec}$. Latencies ranged from .53 to $1.72 \mathrm{sec}$. This range of latencies is considerably greater than that found by Gorfein using a subset of 144 CVC trigrams. Gorfein reported median pronunciation latencies ranging from 1.54 to $2.04 \mathrm{sec}$. The P Lat scores of the present experiment for the same 144 items correlated +.47 with Gorfein's data. Procedural differences between the two experiments are undoubtedly responsible for the relatively low agreement between the two sets of data. Gorfein used a constant presentation rate. This procedural difference may also account for the discrepancies in range and absolute magnitude of $\mathbf{P}$ Lat scores between the two studies.

The distribution of P Lat is extremely leptokurtic and positively skewed as indicated by the fact that $95 \%$ of the trigrams fall within $\pm 1 \mathrm{SD}$. This finding can be taken as evidence that the nonsense syllable is truly a syllable (i.e., it is pronounceable). The fact that $P$ Lat correlated only +.27 with Johnson's (1964) associative latency measure (169 items) suggests that associative factors played a minor role in the $\mathrm{P}$ Lat scores.

$P$ Lat scores accumulated at the lower end of the distribution to suggest a lower limit to P Lat at $.5 \mathrm{sec}$. This lower limit agrees with paired-associate experiments in which the anticipation interval was varied (e.g., Nodine, 1963, 1965). In these studies, it was found that Ss were unable to make an anticipation response under conditions in which the anticipation interval (stimulus duration) was $.5 \mathrm{sec}$.

Because of the shape of the obtained distribution of P Lat, it is suggested that items be classified into three categories of pronunciability according to P Lat: (1) Medium-which includes items ranging from $.686-.945 \mathrm{sec}( \pm .5 \mathrm{SD})$. This range contains 1663 items or $79.2 \%$ of the distribution. (2) High-which includes items from $.531-.675 \mathrm{sec}$. There are 197 items or $9.4 \%$ of the distribution in this range. Referring to Fig. 1, the last item in this range is GAP. (3) Low-which includes items from $.946-1.726 \mathrm{sec}$. There are 240 items or $11.4 \%$ of the distribution in this range. Again referring to Fig. 1, the first item in this range is $\mathrm{KAV}$.

\section{Practice Effects}

Because the order of presentation of each sublist was constant for all Ss, it was necessary to determine whether or not latencies increased from the first to last item in the sublist. Mean latencies for successive blocks of 15 items each were analyzed by analysis of variance. The resulting $F(35,1904)=1.06$ was nonsignificant and it was concluded that $\mathrm{P}$ Lat was unaffected by practice effects.

\section{Repetition Effects}

Each $\mathrm{S}$ pronounced the 525 trigrams of a sublist twice. Average P Lat decreased from .81 to $.76 \mathrm{sec}$ on the second repetition, $F(1,36)=2.97$, n.s. A modified split-half technique was used to obtain a measure of stability of P Lat. Each group of Ss received a different random sublist of the 2100 items. After arranging the latency scores for individual items in increasing order of magnitude for each sublist, correlations were performed on equivalent items between sublists. These six correlations ranged from $\mathrm{r}=.94$ to $\mathrm{r}=.98$, suggesting high intersubject agreement on equivalent items within the list. The procedure of correlating sublists after ranking the items from low to high provides a way of comparing the distribution of P Lat scores for different sublists. The extent to which the distributions of the sublists are similar is reflected by the magnitude of the correlations obtained.

\section{Sublist Effects}

Although Ss were randomly assigned to each of the four sublists, analysis of variance indicated that average $\mathbf{P}$ Lat scores for Sublist 2 were significantly faster than those for Sublists 1, 3, and $4, F(3,56)=6.73, p<.001$. While this difference was a reliable one, the magnitude of the average difference among sublists was relatively small $(.07-.10 \mathrm{sec})$. 


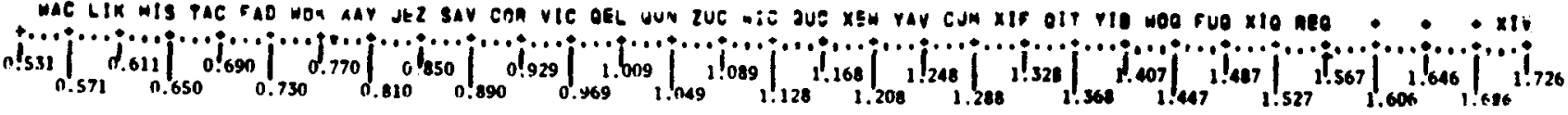

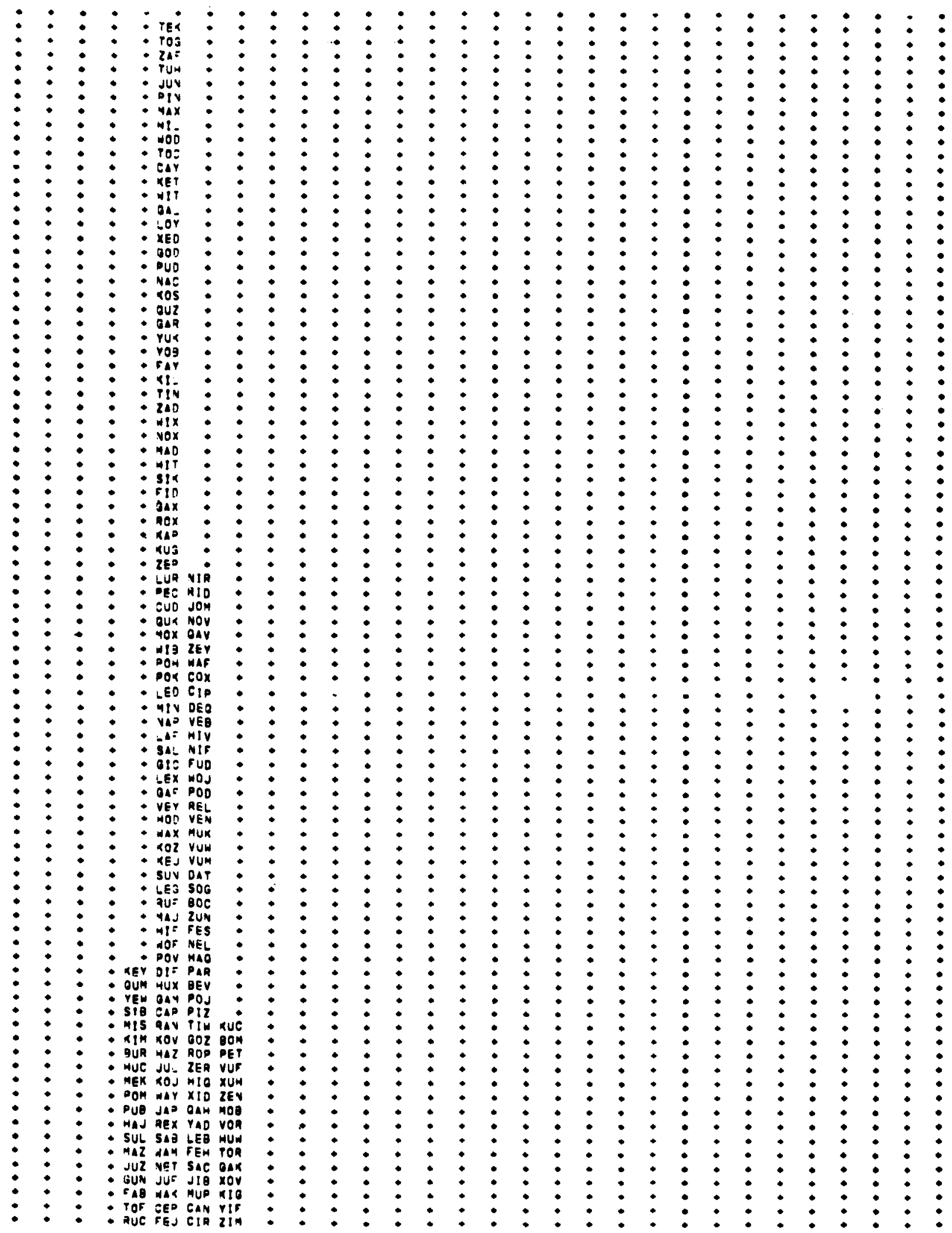

Fig. 1. Frequency histogram showing $P$ Lat values for all $2100 \mathrm{CVC}$ trigrams. P Lat values in a given column are greater than the lower bound and less than the upper bound. (This figure had to be aplit over four pages in order to be bound in the jourmal. But it should be read as though it is one continuous page beginning at the top of this page and running to the bottom of page 215.) 
Figure 1 continued.

- zUn QA. zEF rUC - wel raz nes mon

- nol hel nuj oid

- yol yOK CAS nOR

- ian fer poe xue

- Sox ras sú seg

- noz zar pon via

- xul ala poo ruv

- xut oit oor wua

- oix pur beo vá

- Bic pix gar cia

- zUd das vol coo

- eec dea giv ría

- tan oir jar neo

- lal kel jog var

- mur rus mev pua

- tup mut pan bey

- LUS dor nem zUV

- bod tax mea ber

- dop jol deh fiY

- raj rar fus bov

- KEN JUX DOY zaY

- ilc de Jec puz

- YOH MIH NOW ZUL

- LOS FOH KEF VOH

- hez vel vip max

- rac muv sua gea

- oAs XUS PIL NEh

- dur soz fia zeo

- han oí gin zup

- tea zir vip pia

- Ran mik xah hoy

- vá tol kIS jop

- sim luo jID kor

- yer pua ala bil

- gal ner gor jor

- Jer cax dez oir

- roc nog reo vuY

- pes oem tik dup

- zur dia cor olc

- sum for dok gar

- zit yin yeo vas

- nug vik mak rej

- han jan aon may

- aex rua tij rag

- Lar yus vaz yer

- Dan vox vuc elj

- Par bog num ooc

- Ful hes mox mab

- ma sew PIl xam

- rum ris rón cor

- guar yuo ruo soo

- wr dax kin ron

jex Jev sá oey

- anal nuo ner cin

- vit cua dow CEe

- xes jez olg bia

- ros der mor sio

- Tal bar bio pur

- rev ges pol juy

- vax jar aak pic

- vus nui rao jif

- oar ser oev doo

- mer doc kax al

- Del ver vall xud var

- job oox oac NEo oé

- yop alt wer va mod

- ves oar rex wej xaj

- oir seo bus buv nuJ

- kip lua jon dis xuy

- Tes zi- roj PAC gon

- Feo pua ral zue tec

- Haj ra: alaj 200 2Ex

- Six aes mia oor sie

- oex dea a0z oix zor

- var vej cif vio ove

- rep PEX JAG bas our

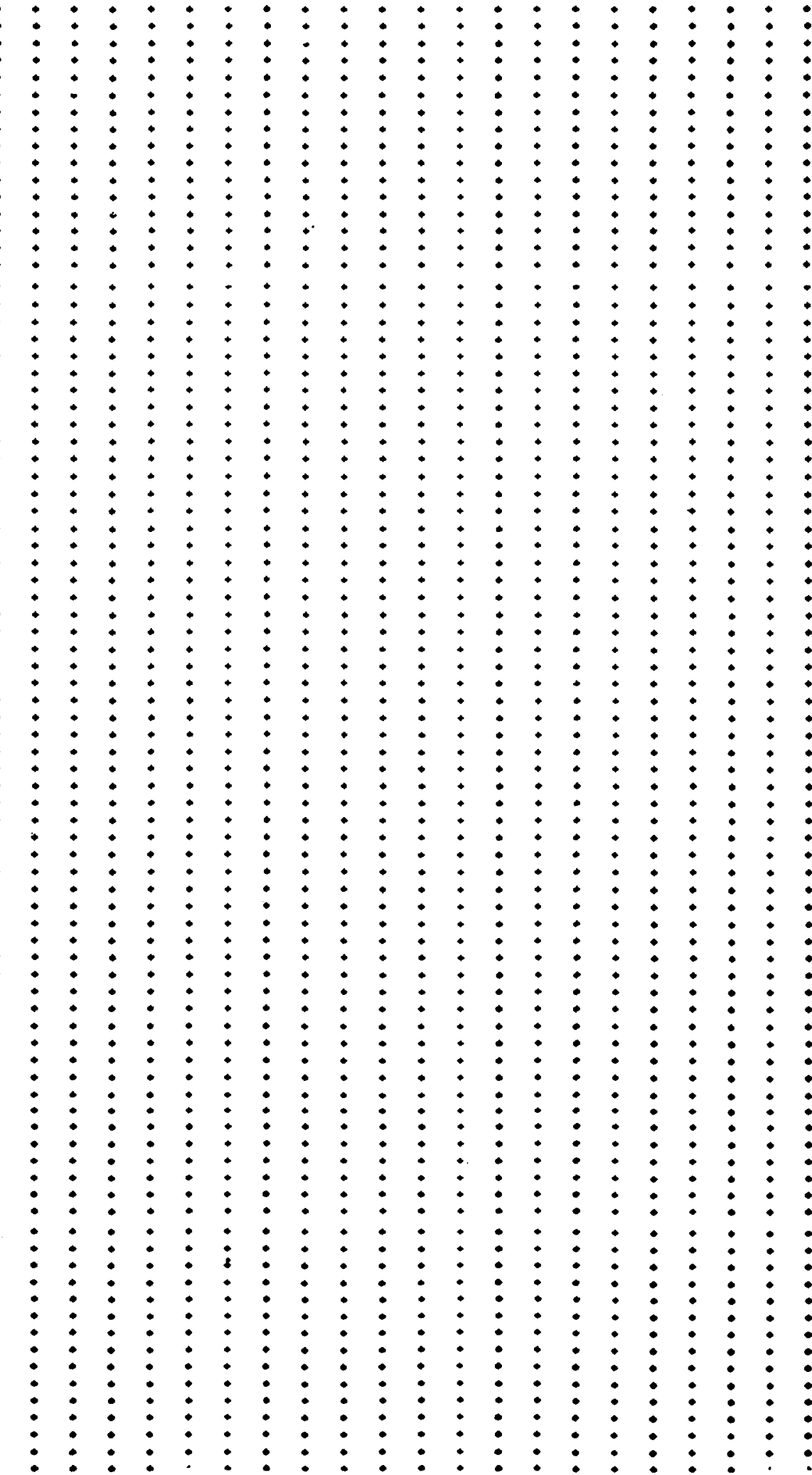

(Continued on next page.) 
Figure 1 continued.
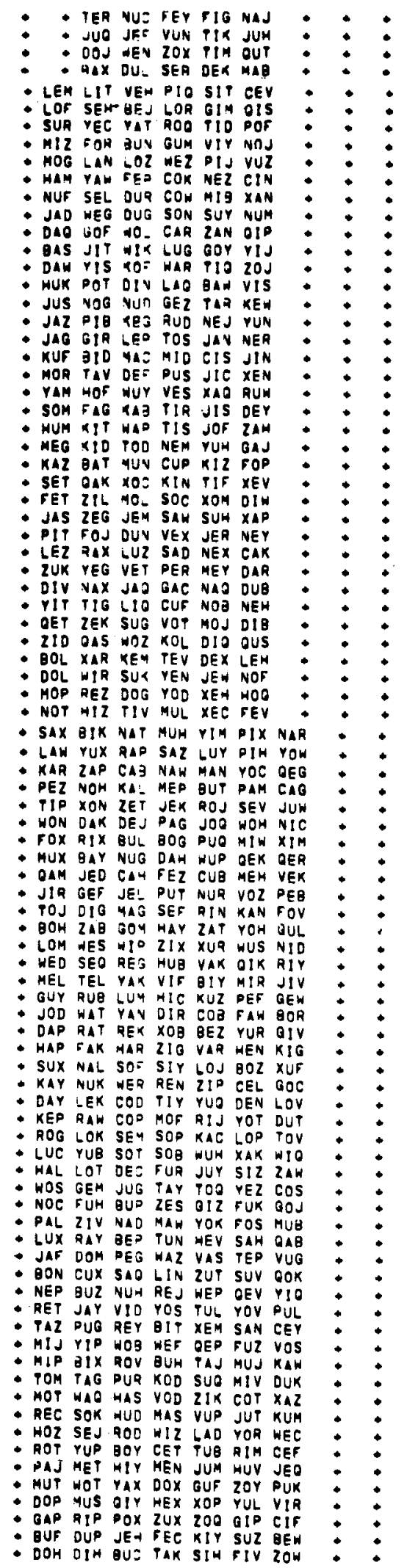

(Continued on next page.) 


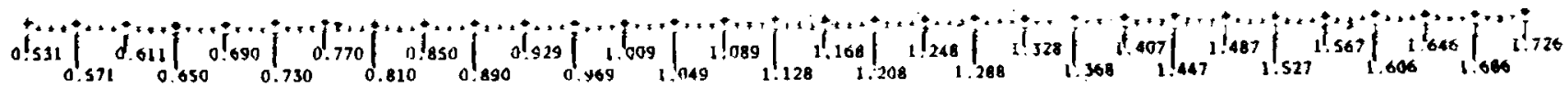




\section{Errors in Measurement}

Two kinds of errors in measuring Ss' pronunciation latencies occurred in the present experiment. One kind of error resulted from erroneous responses due to extraneous noises that triggered the voice key. These were usually characterized by very short latencies (.18 sec or less). Another kind of error resulted from failure of the voice key to trigger because of a soft-spoken response by $S$. These errors were characterized by maximum latencies $(3.0 \mathrm{sec})$.

These two kinds of errors could introduce bias that would affect spuriously the average pronunciation latency for a trigram. In order to reduce these effects, Chauvenet's criterion was used to reject extreme scores (Young, 1962). After deviant scores were rejected, the average latencies were recomputed. The $P$ Lat scores presented for each trigram have been corrected using Chauvenet's criterion.

\section{$P$ Lat and Meaningfulness}

The overall correlation between P Lat and Archer meaningfulness based on 2100 scores was $r=-.37$. Figure 2 shows the relationship between P Lat and Archer (1960) meaningfulness. The $P$ Lat values shown are average $P$ Lat values obtained by summing the $P$ Lat values of individual trigrams contained in successive tenths of the Archer meaningfulness scale and dividing this sum by the appropriate $\mathrm{N}$. The number of CVCs at each of the 10 data points are: $0-10,121 ; 11-20,187 ; 21-30,204 ; 31-40$, $233 ; 41-50,164 ; 51-60,142 ; 61-70,181 ; 71-80,165 ; 81-90,223$; 91-100, 480 .

Figure 2 indicates a linear relationship between $P$ Lat and meaningfulness. This finding is at variance with Underwood and Schulz's conclusions for rated pronunciability, which indicate that the "... rated ease of pronouncing the syllables increases from 0 percent $M$ to approximately 50 percent $M$, with no appreciable change thereafter [p. 282]." Clearly, this is not the case in the present study.

Gorfein suggests that Underwood and Schulz's conclusions regarding the correlation between rated pronunciability and meaningfulness are spuriously high due to the fact that $\mathrm{Ss}^{\prime}$ pronunciability ratings are contaminated by meaningfulness. The findings of the present experiment are consistent with this view. The P Lat measure obtained under a self-paced format appears to be relatively free of bias from other attributes of the stimuli, in particular meaningfulness. Thus, $P$ Lat may be interpreted as reflecting a basic amount of time necessary to process information according to pronunciation rules primarily. As such, the data of the present experiment provide researchers with a unique set of stimulus materials.

\section{REFERENCES}

ARCHER, E. J. A re-evaluation of the meaningfulness of all possible CVC trigrams. Psychological Monographs, 1960, 74, Whole No. 497.

GORFEIN, D. S. Measurement of the pronunciability of CVC trigrams. Psychological Reports, 1967, 21, 879-880.

GOSS, A. E., \& NODINE, C. F. Paired-associates learning. New York: Academic Press, 1965.

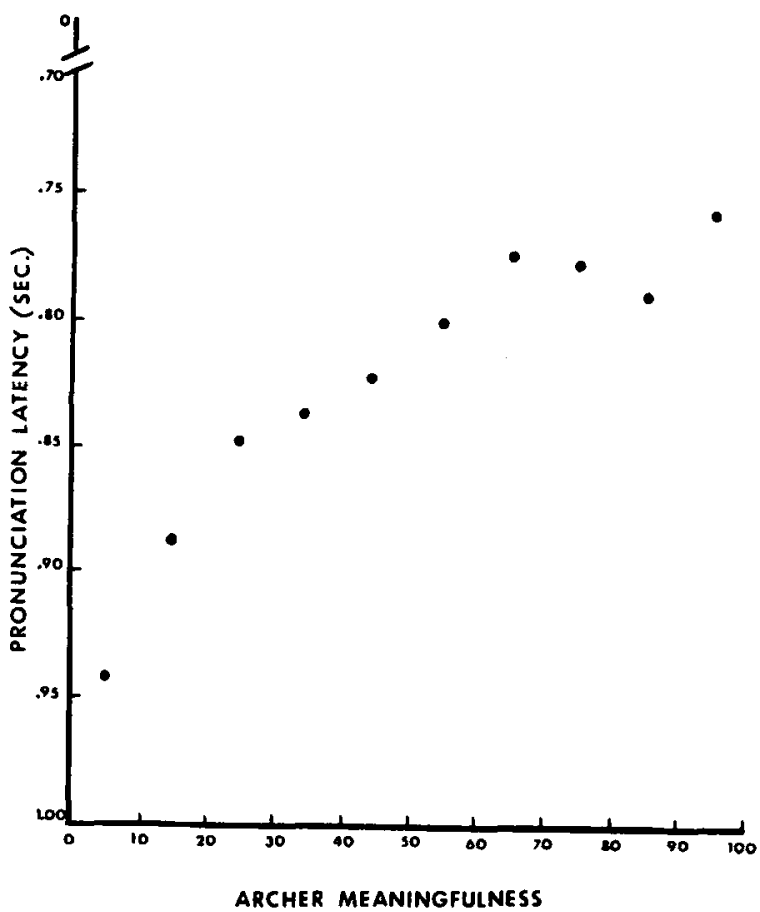

Fig. 2. The relationship between $P$ Lat and Archer meaning fulness. $P$ Lat values represent average values based on the number of trigrams at each level of meaningfulness.

JOHNSON, R. C. Mean associative latencies of $200 \mathrm{CVC}$ trigrams. Journal of Psychology, 1964, 58, 301-305.

NODINE, C. F. Stimulus durations and stimulus characteristics in paired-associates learning. Journal of Experimental Psychology, 1963, $66,100-106$

NODINE, C. F. Stimulus durations and total learning time in paired-associates learning. Journal of Experimental Psychology, 1965, 69,534536 .

UNDERWOOD, B. I., \& SCHULZ, R. W. Meaningfulness and verbal learning. Chicago: Lippincott, 1960.

WILSON, W. R., \& BECKNELL, J. C. The relationship between association value, pronunciability, and affectivity of nonsense syllables. Journal of Psychology, 1961, 52, 47-50.

YOUNG, H. D. Statistical treatment of experimental data. New York: McGraw-Hill, 1962. Pp. 76-79.

\section{NOTES}

1. This research was supported by Grants MH 11974 and MH 07722 from the National Institute of Mental Health, U.S. Public Health Service.

2. Now at Temple University. Reprint requests should be sent to Calvin F. Nodine, Department of Educational Psychology, Temple University, Philadelphia, Pa. 19122.

3. Errors in measuring $P$ Lat due to erroneous responses accounted for $1260 / 21,000$ responses for a $6 \%$ error rate. Because of these errors, 840

4. An alphabetical listing of pronunciation latencies for all $2100 \mathrm{CVC}$ trigrams with standard deviations is available on request to the authors. 